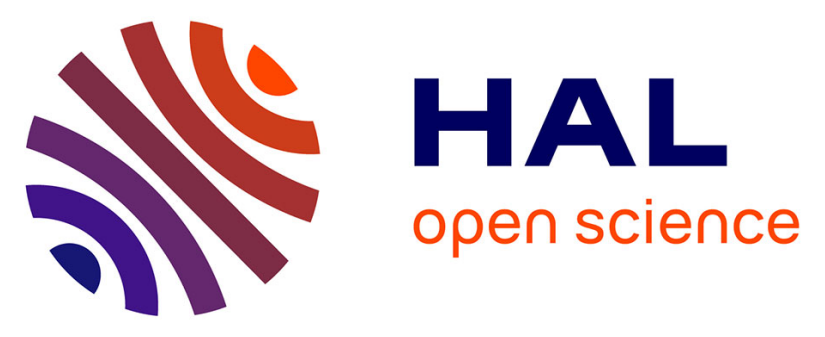

\title{
Effects of low concentrations of deltamethrin are dependent on developmental stages and sexes in the pest moth Spodoptera littoralis
}

Aude Malbert-Colas, Thomas Drozdz, Manuel Massot, Thibaut Bagni, Thomas Chertemps, Annick Maria, Martine Maïbèche, David Siaussat

\section{To cite this version:}

Aude Malbert-Colas, Thomas Drozdz, Manuel Massot, Thibaut Bagni, Thomas Chertemps, et al.. Effects of low concentrations of deltamethrin are dependent on developmental stages and sexes in the pest moth Spodoptera littoralis. Environmental Science and Pollution Research, 2020, 27 (33), pp.41893-41901. 10.1007/s11356-020-10181-9 . hal-03009551

\section{HAL Id: hal-03009551 \\ https://hal.science/hal-03009551}

Submitted on 17 Nov 2020

HAL is a multi-disciplinary open access archive for the deposit and dissemination of scientific research documents, whether they are published or not. The documents may come from teaching and research institutions in France or abroad, or from public or private research centers.
L'archive ouverte pluridisciplinaire HAL, est destinée au dépôt et à la diffusion de documents scientifiques de niveau recherche, publiés ou non, émanant des établissements d'enseignement et de recherche français ou étrangers, des laboratoires publics ou privés. 


\section{Effects of low concentrations of deltamethrin are dependent on developmental stages and sexes in the pest moth Spodoptera} littoralis

Aude Malbert-Colas ${ }^{\mathbf{C O}}$, Thomas Drozdz ${ }^{\mathbf{C O}}$, Manuel Massot, Thibaut Bagni, Thomas Chertemps, Annick Maria, Martine Maïbèche, and David Siaussat*

CO Contributed equally to this work: A. Malbert-Colas and T. Drozdz

Sorbonne Université, CNRS, INRAe, IRD, Institut d'Ecologie et des Sciences de l’Environnement de Paris, iEES-Paris, F-75005, Paris, France

*Corresponding author: Phone: +33 1 44276587. E-mail: david.siaussat@ sorbonne$\underline{\text { universite.fr }}$

\section{Funding}

This research was supported by the CNRS (PEPS FaiDoRA). 


\begin{abstract}
Effects of low concentrations of pesticides, with no or moderate mortality of targeted species, are poorly studied even though these low concentrations are common under natural conditions. Studying their effects is critical because they can induce positive hormetic responses, possibly leading to greater pest multiplication and promoting the evolution of pest resistance. Here, we investigated the responses of the pest moth Spodoptera littoralis to low concentrations of deltamethrin, and tested for variation in effects of the pesticide between developmental stages and sexes. Indeed, we show that a given concentration of deltamethrin has different effects between stages, and even between sexes. Two experimental concentrations led to very high mortality early in S. littoralis development ( $4^{\text {th }}$ larval instar), but only to low mortality rates in adults. Moreover, our highest experimental concentration had only detrimental effects in adult females, but improved the reproductive success of adult males. Model projections showed that the lethality from treatments at the $4^{\text {th }}$ larval instar was the predominant effect. Because of the high multiplication rate of S. littoralis, it was also found that treatments with very similar effects on larval mortality can lead to either population extinction or rapid pest resurgence.
\end{abstract}

\title{
Keywords
}

Pesticide, low-dose effect, hormesis, population growth rate, projection models, crop insect pest. 


\section{Introduction}

The widespread use of pesticides results in environmental pollution, biodiversity loss and the evolution of pest resistance (Casida 2009). Furthermore, in addition to the environmental nuisances and mortality of pests caused by high concentrations of insecticides, lower concentrations of pesticides can have unwanted impacts (Guedes et al. 2016, 2017). Low concentrations of pesticides associated with no or moderate mortality of targeted species can induce positive responses in exposed individuals with hormetic responses that may result in greater pest multiplication and pest resurgence, and promote evolution of pest resistance (Cutler 2013; Guedes et al. 2014). Although widely neglected, these nonlinear dose responses (biphasic response of individuals with low-dose stimulation and high-dose inhibition) are observed in all types of organisms and in response to many chemical and environmental factors (Costantini et al. 2010; Guedes et al. 2014). In the case of pesticides, low concentrations are common under natural conditions. Indeed, pesticide concentrations vary greatly over space and time because of various biotic and abiotic processes (Cutler 2013).

This variation can especially result from concentrations that decrease over time due to the progressive degradation of pesticides, and from the spread of pesticides into the environment outside treated areas. The infrequent cases of partially exposed individuals of targeted species when spraying pesticides in fields could also be considered. Indeed, while most individuals face lethal doses of pesticides when fields are treated, the small proportion of individuals facing lower doses should become a significant proportion of the few surviving individuals. In our study, we considered low concentrations of pesticides with regard to pesticide treatments in fields in order to compare the effects of the same low concentrations between different 
developmental stages. For a sensitive developmental stage, it is therefore possible to induce a high mortality with such low environmental concentrations. In other words, we considered low concentrations of pesticides with regard to agricultural practices, not with regard to the sublethal and lethal effects of pesticides.

Here, we focus on deltamethrin, one of the most widely used synthetic pyrethroids (WHO 1989). Pyrethroids display high efficacy against target insects and decreased toxicity to non-target vertebrates (Bradbury and Coats 1989; Goulding et al. 2013). The molecule induces toxic responses in the central and peripheral nervous systems of insects by interacting with voltage-gated sodium channels (Haug and Hoffman 1990). As a sprayed pesticide (Soderlund 2004), deltamethrin can be spread outside of treated areas. Its persistence in the environment is highly variable with half-lives ranging from 5.7 to 209 days in soil and 5.917.0 days on plants (Johnson et al. 2010). However, its persistence in the environment is generally expected to be moderate as deltamethrin has a high residual activity only in protected environments. This moderate persistence limits the duration of exposure to low concentrations, but opens up the possibility for individuals close to treated fields to quickly encounter low concentrations of deltamethrin. These individuals close to treated fields may be particularly numerous at the specific time of the field treatment. Therefore, low concentrations of deltamethrin are expected for relatively short periods (1-2 weeks) after pesticide spraying in fields and areas close to the treated fields, in addition to the immediate drift of deltamethrin in areas near treated fields. As mentioned above, individuals partially exposed when spraying pesticides in fields could also be considered for exposure to low concentrations of deltamethrin.

Our research group previously found hormetic effects of deltamethrin in the moth Spodoptera littoralis (Lalouette et al. 2016). In this study spanning levels from genes to 
behaviour, it was shown that a low concentration of deltamethrin stimulates male sexual behaviour. Relationships found at the molecular level suggested that this hormetic effect was due to protection of the olfactory system by induced expression of various biotransformation enzymes (including cytochromes P450 and glutathione-S-transferases) and modulation of olfactory actors (antennal-specific carboxylesterases and odorant-binding proteins) after exposure to deltamethrin. These responses may be crucial as the olfactory system enables this moth to search for mating partners (male attraction to female-produced sex pheromone), egglaying sites and food sources. In the present study, we expand the scope of our tests on the responses of $S$. littoralis to low concentrations of deltamethrin. We were interested in testing the effects of deltamethrin between sexes and different developmental stages of the moth, especially because pesticide effects can vary between developmental stages (Christie and Wright 1990; Bouvier et al. 2002; Germano and Picollo 2018). We therefore conducted experimental series on fourth-stage larvae and adults. The moth traits investigated were larval mortality, adult mortality, and adult reproduction (clutch size and hatching success). We used population projection models to evaluate the relative importance of the response of the different moth traits tested. The observed responses were compared with estimates of the asymptotic growth rate obtained from a matrix modelling of the life cycle of S. littoralis.

\section{Materials and Methods}

\section{Study system}

We studied the cotton leafworm Spodoptera littoralis, a major pest insect. The larvae of this widespread African and Mediterranean moth damage 87 plant species of economic importance such as cotton, maize, and tomato (CABI 2020), making this species one of the 
most destructive agricultural pests. This species can complete two to seven generations per year (Khafagi et al. 2016). Its larval development is complete with six or seven instars (depending on environmental conditions, Baker and Miller 1974), and the last two larval instars induce approximately 90 to $95 \%$ of plant defoliation (Khafagi et al. 2016). A laboratory strain of S. littoralis was used in our study. Larvae were reared on a semi-artificial diet (Hinks and Byers 1976) at $23^{\circ} \mathrm{C}$ and a 60-70\% relative humidity, with a 16:8 light/dark cycle until emergence. Individuals were sexed as pupae.

\section{Experiments}

The test solutions were prepared with deltamethrin (45423, Sigma Pestanal, France) diluted in a pure hexane solution (Abdullah et al. 2015; Kraikrathok et al. 2013). In each of our experimental series, these treatments were compared to a control group treated with only hexane. In preliminary tests of the study of Lalouette et al. (2016), several solvents were tested (hexane, acetone, ethanol) and only hexane had no or a very low toxicity. This is also shown in the present study with high survival rates in the control groups treated with hexane. We treated larvae at the fourth larval instar (hereafter referred as L4) to test the effects of pesticide on larval survival rate. Topical applications of $0.5 \mu \mathrm{L}$ of the test solutions to the head of L4 larvae were performed using a micro-applicator (Hamilton $25 \mu \mathrm{L}$ syringe and Hamilton dispenser). The effect on larval survival was assessed on the basis of the survival rate until pupation, i.e. under a period of 13 days between the topical application applied at the beginning of the L4 stage and pupation. Treatments were also applied to two-day-old adults of both sexes to test for effects on adult survival and reproduction. We topically applied a $0.5 \mu \mathrm{L}$ drop to each antenna. The effect on adult survival was assessed based on the survival rate 24 hours after treatment, as in Lalouette et al. (2016). Effects on reproduction were 
assessed based on the number of eggs laid (collected 24 hours after mating) and hatching success. To investigate the respective sensitivities of reproduction to deltamethrin of adult females and males, and potential combined effects, we performed experiments with deltamethrin treatments applied to both parents, only females, and only males.

The choice of the route of exposure is a sensitive issue when testing the effects of pesticides because pests can be exposed through different routes (contact during pesticide spraying, contact and ingestion after pesticide treatments) and the variety of protocols is wide (e.g., see https://irac-online.org/methods/). Our methodological choice of topical applications of deltamethrin was initially adopted to standardize our experimental treatments as much as possible. Indeed, treatments with small amounts of pesticides can be particularly sensitive to biases (e.g., variation in feeding activity between experimental individuals with an ingestion method, variation in movements with a spraying on experimental surfaces). Our choice of topical applications on the antennae of adults and the head of larvae (small antennae size) was secondly based on our previous finding that a drop deposited on antennae is an effective application mode to induce hormetic effects with low concentrations of deltamethrin in S. littoralis (Lalouette et al. 2016). The main cause assumed for the high sensitivity of this route of exposure is that the multiporous structure of the cuticular olfactory hairs facilitates insecticide penetration into the insect body.

We selected low concentrations of deltamethrin based on recommended concentrations in fields and the previous study of adult males of S. littoralis (Lalouette et al. 2016). The recommended doses of deltamethrin to treat fields are 6.25 and $35 \mathrm{~g}$ of active ingredients per hectare and correspond to the spraying of pure solutions (usually at $25 \mathrm{~g} / \mathrm{L}$ ) diluted from 500 to 3,000 fold (Chowdhury et al. 2001; Sharma et al. 2018). The insects are thus exposed just after spraying to diluted solutions approximatively from 8 to $50 \mathrm{mg} / \mathrm{L}$. We selected the three 
following concentrations of deltamethrin for our tests: $0.076,0.76$ and $5.05 \mathrm{mg} / \mathrm{L}$ of deltamethrin. Although our highest concentration is close to the inferior limit of the concentration recommended for spraying, we considered it as a low environmental concentration for two reasons. First, we performed only a single topical application of the test solutions on experimental animals whereas it can be expected repeated exposures in fields. Second, our topical applications of the test solutions were performed with only the half of the solution used in Lalouette et al. (2016) where our highest concentration $(5.05 \mathrm{mg} / \mathrm{L})$ of deltamethrin induced $30 \%$ mortality in adult males.

\section{Statistical analyses}

We analysed our binomial data on larval, pupal and adult survival using logistic analyses with deltamethrin treatments (including the control group) as a factor. We took sex and its interaction with the deltamethrin into account in analyses of pupal and adult survival rates. We also used logistic analyses to analyse clutch success because the hatching success of laid eggs strongly deviated from normality. We created two classes of clutch success: clutches with at least $95 \%$ of hatched eggs (135 clutches) and clutches with more than $5 \%$ of unhatched eggs ( 89 clutches). The value of this split was chosen to balance the sample size between the two classes. To analyse clutch success, we included treatment group (experimental treatments of both parents versus only females versus only males) and its interaction with deltamethrin as factors. We also included the factor date in the analyses. Experiments were performed on several dates for the tests of survival of L4 larvae (2 experimental dates) and adults (6 dates in females and 9 in males), and for the tests of clutch success ( 6 dates with both parents treated, 4 dates with females treated and 6 dates with males treated). Sample sizes per experimental date are given in Online Resource 1. In our analyses 
that combined the date of experiment, sex or treatment group factor with deltamethrin, we selected models after backward elimination of independent factors for which $P>0.10$.

For the analysis of the number of eggs laid, the only continuous dependent variable we analysed, we used mixed-effects linear models with deltamethrin treatment, treatment group and their interaction as fixed effects, and with the date of experiments included as a random factor ( 6 dates with both parents treated, 4 dates with females treated, and 6 dates with males treated). We checked the residuals of the initial model for normality and homoscedasticity, and full models were simplified by backward stepwise removal of terms for which $P>0.10$.

\section{Projection matrix models}

In order to evaluate the relative importance of the response of the different moth traits tested, we build matrix models to estimate the multiplication rate at the population level (Caswell 2001). Precisely, we used the asymptotic growth rate (i.e., intrinsic rate of increase) as a proxy for population dynamics (Caswell 2001; Metcalf and Pavard 2007). As usual for this kind of demographic modelling, our models were based solely on females. This approach assumes that male abundance is always high enough to ensure reproduction of most females (Bessa-Gomes et al. 2010). This assumption was relevant to our study, where the sex-ratio was nearly balanced (see Online Resource 2). We modelled the life cycle of S. littoralis from an age-structured matrix where each age class was of 1 day, and we calculated the population growth rate as the dominant eigenvalue of the matrix. We parameterised this daily matrix model with the vital parameters estimated in the present study (survival from the fourth larval instar to pupation, pupal survival, adult female survival, laying success after mating, number of eggs laid, and hatching success). We used values obtained from a complementary study in 2017 with the same rearing conditions for survival between the first and fourth larval instars, 
sex-ratio, and duration of the different developmental periods. All the values used in the models are given in Online Resource 2. Our modelling was performed with the computer program ULM ('Unified Life Models') (Legendre and Clobert 1995; Ferrière et al. 1996). The ULM program can be downloaded from http://www.biologie.ens.fr/ legendre/ulm/ulm.html. This program enabled us to estimate the growth-rate sensitivity and elasticity (i.e., relative sensitivity) to change in the different vital parameters tested (Caswell 2001; Ferrière et al. 1996).

\section{Results}

\section{Larval survival rate}

Figure 1 shows the mortality effect of deltamethrin on larvae treated at stage L4. Deltamethrin decreased larval survival rate until pupation $\left(X^{2}{ }_{3}=189.4 P<0.001\right)$. The experimental group with the lowest concentration of deltamethrin $(0.076 \mathrm{mg} / \mathrm{L})$ did not differ from the control groups $\left(X^{2}{ }_{1}=0.9 P=0.345\right)$. However, very few L4 larvae treated with the two highest concentrations of deltamethrin survived until pupation (only 3 of the 60 L4 larvae treated with $0.76 \mathrm{mg} / \mathrm{L}$ of deltamethrin, and none of the $60 \mathrm{~L} 4$ larvae treated with $5.05 \mathrm{mg} / \mathrm{L}$ ).

\section{Adult survival rate}

Because we observed variation in the adult survival rate among the experimental dates $\left(X^{2}{ }_{5}=15.1 P=0.010\right.$ in females; $X^{2}{ }_{8}=26.3 P=0.001$ in males $)$, we made a special effort to replicate our tests on the effect of deltamethrin on adults. Therefore, we performed our tests on 528 adult females on 6 experimental days, and on 445 adult males on 9 experimental days. We found a significant effect of deltamethrin on the adult survival rate in females $\left(X^{2}{ }_{3}=13.5\right.$ 
$P=0.004)$ and males $\left(X^{2}{ }_{3}=8.5 P=0.036\right)$. Compared to the control group, the highest concentration $(5.05 \mathrm{mg} / \mathrm{L})$ of deltamethrin decreased the adult survival rate (Fig. 2) of both females $\left(X^{2}{ }_{1}=6.4 P=0.011\right)$ and males $\left(X^{2}{ }_{1}=6.8 P=0.009\right)$. Adult survival did not significantly respond to the $0.76 \mathrm{mg} / \mathrm{L}$ concentration (females: $X^{2}{ }_{1}=1.3 P=0.258$; males: $X^{2}{ }_{1}=0.9 P=0.343$ ), or the $0.076 \mathrm{mg} / \mathrm{L}$ concentration (females: $X^{2}{ }_{1}=3.1 P=0.077$; males: $X^{2}{ }_{1}=1.9 P=0.167$ ).

\section{Number of eggs laid}

We first analysed clutch size using a mixed-effects linear model with the deltamethrin treatment, treatment group (treatment of both parents versus only females versus only males) and their interaction as fixed effects, and the date of the experiments as a random factor. We did not find significant variation in clutch size among the dates of the experiments (Wald ztests: $P=0.340$ with deltamethrin applied to both parents, $P=0.336$ for treated females, and $P=0.102$ for treated males). Consequently, we analysed the clutch size with ANOVA, crossing the effects of deltamethrin and treatment groups. We detected an effect of deltamethrin $\left(F_{3,218}=9.2 P<0.001\right)$, and this effect did not significantly differ among treatment groups $\left(F_{6,212}=0.5 P=0.785\right.$ for the interaction between deltamethrin and treatment groups $)$.

Figure 3 shows that the clutch size was decreased by the treatment with $5.05 \mathrm{mg} / \mathrm{L}$ of deltamethrin. This effect on the number of eggs laid was significant for deltamethrin applied to both parents $\left(\mathrm{t}_{48}=-87.8 P<0.001\right)$ or to females $\left(\mathrm{t}_{30}=-9.8 P=0.037\right)$, but not significant for deltamethrin applied to males $\left(\mathrm{t}_{33}=34.6 P=0.165\right)$. Clutch size was not significantly influenced by the treatment with deltamethrin concentrations of $0.076 \mathrm{mg} / \mathrm{L}(P>0.243)$ and $0.76 \mathrm{mg} / \mathrm{L}$ $(P>0.306)$ in the three treatment groups. It should be noted that the high values of s.e.m. of the number of eggs laid reported in the figure 3 were observed in another study on $S$. 
littoralis, and that this variation was at least partly explained by the female body mass (unpublished data).

\section{Clutch success}

We found that clutch success depended on clutch size $\left(X^{2}{ }_{1}=26.2 P<0.001\right)$. Indeed, the larger the number of eggs laid was, the more successful the clutches were (higher frequency of clutches with at least $95 \%$ hatched eggs), as illustrated in Fig. 4 for our experimental series on the treatment of males. The relationship between clutch size and success did not depend on the deltamethrin treatment $\left(X^{2}{ }_{3}=2.5 P=0.476\right)$ or treatment group $\left(X^{2}{ }_{2}=0.3 P=0.846\right)$. However, the average effect of deltamethrin significantly differed between the treatment groups $\left(X^{2}{ }_{6}=13.9 P=0.031\right)$. Indeed, we found a significant effect of deltamethrin only in experiments on males. The males treated with the highest concentration of deltamethrin had the highest clutch success (Fig. $4 ; X^{2}{ }_{1}=6.2 P=0.013$ ). However, the highest concentration of deltamethrin had no significant effect when applied to females $\left(X^{2}{ }_{1}<0.1 P=0.905\right)$ or both to males and females $\left(X^{2}{ }_{1}=3.0 P=0.084\right)$. The deltamethrin concentrations of 0.76 and 0.076 $\mathrm{mg} / \mathrm{L}$ did not significantly affect the clutch success in the three treatment groups $(P>0.10)$.

\section{Projection models}

To integrate the different observed responses and evaluate their relative importance, we parameterised our models with regard to the significant effects of deltamethrin found in our experiments. The values used to fix the parameters are given in Online Resource 2. We modelled scenarios for the treatments applied specifically to the different developmental stages and sexes (L4, adult males and females, adult females only, and adult males only), and 
a scenario that combined the values of the treatments applied to all individuals. Because the highest concentration $(5.05 \mathrm{mg} / \mathrm{L})$ of deltamethrin applied to the $\mathrm{L} 4$ stage induced the mortality of all individuals (Fig. 1), it led to population extinction with a multiplication rate of 0 when applied to all stages or only the L4 stage (Fig. 5). All other scenarios resulted in a population increase (multiplication rate $>1$ ). However, the magnitude of the population increase differed among scenarios. Compared to the control group, the intermediate concentration of deltamethrin $(0.76 \mathrm{mg} / \mathrm{L})$ had the strongest negative impact on the multiplication rate when applied to the L4 stage, resulting also in a strong effect when applied to all stages (Fig. 5). This intermediate concentration had almost no effect on the multiplication rate when applied to the adult stage. The highest concentration $(5.05 \mathrm{mg} / \mathrm{L})$ induced weak effects when applied to the adult stages, but with a slight difference between the deltamethrin treatments of adult males and females. The higher multiplication rate in treated males was explained by their higher clutch success (Fig. 4). At the end of the spectrum of population responses to deltamethrin, the lowest concentration of deltamethrin $(0.076$ $\mathrm{mg} / \mathrm{L}$ ) did not affect the vital rates tested in our study and consequently led to the same multiplication rate as the control in all treatment scenarios.

We performed an elasticity analysis to estimate the sensitivity of the multiplication rate to proportional change in the vital rates we tested. From these relative sensitivities, the elasticity analysis allows comparison of the impact of variation in parameters of different types (Caswell 2001; Ferrière et al. 1996). The elasticity analysis shows the highest sensitivities of multiplication rate to variation in larval and pupal survival rates, and low sensitivities for adult survival and reproduction. The elasticity was 0.30 for survival from the L4 stage to pupation, 0.35 for pupal survival, 0.02 for adult survival, 0.02 for clutch size, and 0.09 for hatching success. This analysis explains that the observed effects of deltamethrin on 
adult survival and reproduction induced only minor responses at the population level in the treatment focused on adults (Fig. 5), despite the quite large effects of deltamethrin on clutch size (Fig. 3) and clutch success (Fig. 4). The high elasticity for survival from the L4 stage to pupation combined with the strong effect of the intermediate concentration $(0.76 \mathrm{mg} / \mathrm{L})$ of deltamethrin when applied at the L4 stage (Fig. 1) explains the strong impact at the population level of this intermediate concentration. Although this intermediate concentration and the highest concentration $(5.05 \mathrm{mg} / \mathrm{L})$ had very similar effects on the survival of L4 larvae (see

Fig. 1), their impact on the population differed dramatically, with a population increase for the intermediate concentration versus a population extinction for the highest concentration (Fig. 5). This difference resulted from the mortality of all larvae at the highest concentration, whereas $5 \%$ of larvae survived at the intermediate concentration. Such a qualitative difference in larval mortality is relevant in the context of pest management because the survival of a few individuals of a species with a high multiplication rate, such as $S$. littoralis, is enough to lead to a quick resurgence of pest populations (see Online Resource 3 for projections obtained from the values of vital parameters estimated in the control group).

\section{Discussion}

We report variation in the effects of deltamethrin between larvae and adults of S. littoralis. Deltamethrin is mainly used against the larval stages of S. littoralis in order to fight the pest as soon as possible (Riskallah 1980; Miles and Lysandrou 2002). However, adults are simultaneously affected by the pesticide when different overlapping generations are present in the treated field or areas closed to the treated field. Our study stressed that low environmental concentrations of deltamethrin can have major effects. Indeed, we found that even our intermediate concentration $(0.76 \mathrm{mg} / \mathrm{L})$ of deltamethrin led to very high mortality early in the 
development of S. littoralis, at its fourth larval instar. By contrast, our highest concentration $(5.05 \mathrm{mg} / \mathrm{L})$ of deltamethrin induced only low mortality rates in adults. Interestingly, the highest concentration was detrimental to clutch size but beneficial to the reproductive success of adult males. To summarize, our results show that a particular concentration of pesticide can have different effects depending on individuals in terms of the magnitude of the responses as well as their direction (detrimental versus beneficial). Furthermore, the significance of the observed responses at the population level was highly variable. Our model projections emphasize the prominent influence of effects at early developmental stages, and show also the narrow limit of these early effects leading to either population extinction or population growth.

The early developmental stage studied (the fourth larval instar) was more sensitive to deltamethrin than the adult stage (Fig. 1, 2 and 5). There are three possible causes for this difference: $(i)$ the quantity of pesticide applied to individuals was a function of their body mass, (ii) developmental stages differed in their sensitivity to pesticides, and (iii) the duration considered to test the effects of treatments differed between stages depending on the variables measured. The first explanation related to variation in body mass is likely relevant because body mass differs greatly among stages. Average dry weight is $1.5 \mathrm{mg}$ in L4 larvae, $47.9 \mathrm{mg}$ in adult males, and $63.2 \mathrm{mg}$ in adult females (estimates obtained from live body mass measured in several experimental series on 1256 L4 larvae, 169 adult males and 163 adult females, and using stage-specific ratios between live and dry weight). Thus, L4 larvae were 32 times lighter than adult males, and 42 times lighter than adult females. We accounted for only a small part of the variation between L4 larvae and adults in our treatments by applying 2 times less of experimental solution to larvae than to adults $(0.5 \mu \mathrm{L}$ per larva versus $1 \mu \mathrm{L}$ per adult). Consequently, the amount of deltamethrin provided per insect was 16 times higher in 
L4 larvae than adult males and 21 times higher in L4 larvae than adult females, and should be the main cause of the strongest response observed in L4 larvae. However, the second possibility remains open, with developmental stages that differed in their sensitivity to deltamethrin. Indeed, age dependence on the toxicity of another pesticide (abamectin) between larval instars of S. littoralis was previously observed (Christie and Wright 1990). The suggested mechanisms were age variation in cuticular penetration and metabolic processes. Moreover, the age dependence in response to deltamethrin in another moth species, the codling moth Cydia pomonella, was considered as part of explanation of the evolution of deltamethrin resistance (Bouvier et al. 2002). The third explanation related to the duration considered to test the effects of treatments can be rejected. The large difference in duration between our larval and adult treatments (13 days for L4 larvae versus only 24 hours for adults) is indeed not a concern because the response of larvae to deltamethrin is very rapid (Online Resource 4). In this complementary experiment, high mortality in response to deltamethrin was observed for our highest concentration of $5.05 \mathrm{mg} / \mathrm{L}$, but not for the intermediate concentration of $0.76 \mathrm{mg} / \mathrm{L}$ (Online Resource 4). This difference with our previous result (Fig. 1) shows that the limit between high and low mortality effects on L4 larvae is very close to a deltamethrin concentration of $0.76 \mathrm{mg} / \mathrm{L}$.

Low concentrations of pesticides are more and more studied because they are common outside the treated areas and inside these areas after high lethal concentrations decline with degradation (Cutler 2013). The infrequent cases of individuals partially exposed during pesticide spraying in fields might also to be considered as they could be a significant part of the few individuals surviving to pesticide treatments. Even if low lethal concentrations are less influential on population dynamics than high lethal concentrations in the short-term, they may lead to greater pest multiplication later because they can promote hormetic responses 
with the stimulation of exposed individuals (Cutler 2013; Guedes et al. 2014). Concerning deltamethrin specifically, low concentrations can influence the reproduction of pest insects (Cutler 2013; Lee et al. 1998; Yang and Du 2003), especially in males of S. littoralis (Lalouette et al. 2016). Here, we also found effects of deltamethrin on reproduction, but with a difference between males and females. The effect of our highest concentration of deltamethrin $(5.05 \mathrm{mg} / \mathrm{L})$ was detrimental to the clutch size produced by females, but beneficial to the clutch success of males. This concentration of deltamethrin is considered a low lethal concentration in adults because more than $80 \%$ of adults survived in this treatment (Fig. 2). Consequently, the beneficial response of clutch success of adult males to the 5.05 $\mathrm{mg} / \mathrm{L}$ concentration might be a hormetic response.

In S. littoralis, a hormetic effect on male sexual behaviour was previously found (Lalouette et al. 2016), but for our intermediate concentration $(0.76 \mathrm{mg} / \mathrm{L})$. The lower concentration needed to detect this hormetic effect might be explained by the high sensitivity of behaviours to toxicants (Gerhardt 2007). To be considered hormetic, the response of individuals has to be biphasic, with low-dose stimulation and high-dose inhibition (Costantini et al. 2010; Guedes et al. 2014). Male sexual behaviour was indeed stimulated by the 0.76 $\mathrm{mg} / \mathrm{L}$ concentration and inhibited by the $5.05 \mathrm{mg} / \mathrm{L}$ concentration. Concerning the clutch success of males, we do not know if the stimulation by the $5.05 \mathrm{mg} / \mathrm{L}$ concentration is coupled with an inhibition by a higher concentration. If the response of clutch success is not biphasic, an alternative hypothesis to hormesis is that the stimulation of clutch success by deltamethrin results from an adaptive response of males to the decrease in their survival (Fig. 2). Indeed, a shortening of life expectancy can induce terminal investment in reproduction (Stearns 1992), which might be a fertility insurance response of males to improve their clutch success. This kind of response is expected when males have multiple reproductions, as 
observed in males of S. littoralis which can mate five times on average (Kehat and Gordon 1975). Because Kehat and Gordon estimated that females mate only two times on average, improving their clutch success in response to the decrease in their survival would not be very beneficial, which might explain the lack of stimulation of their clutch success by deltamethrin.

Although insufficiently used, population modelling in ecotoxicology is increasingly advised as a way to translate responses from individuals to the population level (Köhler and Triebskorn 2013; Moe et al. 2013). Here, our models showed that the different vital parameters do not impact populations similarly, and that $S$. littoralis is mostly affected by the pesticide early in development. As a consequence, even our intermediate concentration of deltamethrin is sufficient to have a large effect at the population level. Another lesson of our projection models is that pesticide treatments with nearly lethal effects can lead to either population extinction or pest resurgence. In our experiments, the limit between these two extreme responses resulted from a qualitative difference, namely, that the pesticide treatment killed either all or almost all individuals. This result is not that surprising for S. littoralis, for which we estimated that one to five clutches are sufficient to produce between 200 and 1,300 L4 larvae (Online Resource 3) some days later: 13 days at our experimental temperature of $23^{\circ} \mathrm{C}, 10$ days at $25^{\circ} \mathrm{C}, 9$ days at $27^{\circ} \mathrm{C}$, or 8 days at $29^{\circ} \mathrm{C}$ (unpublished data). In the next generation, the number of L4 larvae will be between 10,000 and 80,000 (Online Resource 3), i.e., 41 days later at $23^{\circ} \mathrm{C}, 34$ days later at $25^{\circ} \mathrm{C}, 29$ days later at $27^{\circ} \mathrm{C}$, and only 27 days later at $29^{\circ} \mathrm{C}$.

The next step in our study will be to investigate the influence of temperature on the effects of deltamethrin. Indeed, Riskallah (1984) found that deltamethrin is more toxic to larvae (at the fourth instar L4) at $20^{\circ} \mathrm{C}$ than at $35^{\circ} \mathrm{C}$. We aim to investigate this response along 
a thermal gradient because of the non-linearity of most biological responses to temperature (Sinclair et al. 2016). It is crucial to study the interaction between pesticides and temperature in the context of global climate change (Hooper et al. 2013), and also to develop predictive insect population models that consider multiple factors simultaneously (Bewick 2016). We also aim to compare different routes of pesticides exposure (topical applications on antenna, proboscis, abdomen and tarsus) that is a sensitive point to investigate the impact of pesticides.

\section{References}

Abdullah F, Subramanian P, Ibrahim H, Abdul Malek SN, Lee GS, Hong SL (2015) Chemical composition, antifeedant, repellent, and toxicity activities of the rhizomes of Galangal, Alpinia galanga against asian subterranean termites, Coptotermes gestroi and Coptotermes curvignathus (Isoptera: Rhinotermitidae). Journal of Insect Science 15:1-7. https://doi.org/10.1093/jisesa/ieu175

Baker CRB, Miller GW (1974) Some effects of temperature and larval food on development of Spodoptera littoralis (Boisd.) (Lep., Noctuidae). B Entomol Res 63:495-511

Bessa-Gomes C, Legendre S, Clobert J (2010) Discrete two-sex models of population dynamics: On modelling the mating function. Acta Oecol 36:439-445. https://doiorg.inee.bib.cnrs.fr/10.1016/j.actao.2010.02.010

Bewick S (2016) Current and future challenges of predictive insect population modelling. Funct Ecol 30:1028-1029. https://doi.org/10.1111/1365-2435.12678

Bouvier JC, Boivin T, Beslay D, Sauphanor B (2002) Age-dependent response to insecticides and enzymatic variation in susceptible and resistant codling moth larvae. Arch Insect Biochem 51:55-66. https://doi.org/10.1002/arch.10052 
Bradbury SP, Coats JR (1989) Toxicokinetics and toxicodynamics of pyrethroid insecticides in fish. Environ Toxicol Chem 8:373-380

CABI (2020) Spodoptera littoralis (cotton leafworm). In: Invasive Species Compendium. Wallingford, UK: CAB International. http://www.cabi.org/isc/datasheet/51070

Casida JE (2009) Pest toxicology: the primary mechanisms of pesticide action. Chem Res Toxicol 22:609-619. https://doi.org/10.1021/tx8004949

Casida JE, Gammon DW, Glickman AH, Lawrence LJ (1983) Mechanisms of selective action of pyrethroid insecticides. Ann Rev Pharmacol 23:413-438

Caswell H (2001) Matrix Population Models: construction, analysis, and interpretation. Sinauer Associates Inc. (2nd edition), Sunderland

Chowdhury ABMNU, Jepson PC, Howse PE, Ford MG (2001) Leaf surfaces and the bioavailability of pesticide residues. Pest Manag Sci 57:403-412. https://doi.org/10.1002/ps.311

Christie PT, Wright DJ (1990) Activity of abamectin against larval stages of Spodoptera littoralis boisduval and Heliothis armigera hübner (Lepidoptera: Noctuidae) and possible mechanisms determining differential toxicity. Pestic Sci 29:29-38

Costantini D, Metcalfe NB, Monaghan P (2010) Ecological processes in a hormetic framework. Ecol Lett 13:1435-1447. https://doi.org/10.1111/j.14610248.2010.01531.x

Cutler GC (2013) Insects, insecticides and hormesis: evidence and considerations for study. Dose-Response 11:154-177. https://doi.org/10.2203/dose-response.12-008.Cutler 
Delpuech JM, Dupont C, Allemand R (2012) Effects of deltamethrin on the specific discrimination of sex pheromones in two sympatric Trichogramma species. Ecotox Environ Safe 84:32-38. https://doi.org/10.1016/j.ecoenv.2012.06.007

Desneux N, Decourtye A, Delpuech JM (2007) The sublethal effects of pesticides on beneficial arthropods. Annu Rev Entomol 52:81-106. https://doi.org/10.1146/annurev.ento.52.110405.091440

Ferrière R, F Sarrazin, S Legendre, J-P Baron (1996) Matrix population models applied to viability analysis and conservation: Theory and practice with ULM software. Acta OEcol 17:629-6356

Gerhardt A (2007) Aquatic behavioral ecotoxicology-prospects and limitations. Hum Ecol Risk Assess 13:481-491. https://doi.org/10.1080/10807030701340839

Germano MD, Picollo MI (2018) Stage-dependent expression of deltamethrin toxicity and resistance in Triatoma infestans (Hemiptera: Reduviidae) from Argentina. J Med Entomol XX:1-5. https://doi.org/10.1093/jme/tjy017

Goulding AT, Shelley LK, Ross PS, Kennedy CJ (2013) Reduction in swimming performance in juvenile rainbow trout (Oncorhynchus mykiss) following sublethal exposure to pyrethroid insecticides. Comp Biochem Phys C 157:280-286. https://doi.org/10.1016/j.cbpc.2013.01.001

Guedes RNC, Cutler GC (2014) Insecticide-induced hormesis and arthropod pest management: insecticide-induced hormesis. Pest Manag Sci 70:690-697. https://doi.org/10.1002/ps.3669 
Guedes RNC, Smagghe G, Stark JD, Desneux N (2016) Pesticide-induced stress in arthropod pests for optimized integrated pest management programs. Annu Rev Entomol 61:4362. https://doi.org/10.1146/annurev-ento-010715-023646

Guedes RNC, Walse SS, Throne JE (2017) Sublethal exposure, insecticide resistance, and community stress. Curr Opin Insect Sci, 21:47-53. https://doi.org/10.1016/j.cois.2017.04.010

Haug G, Hoffman H (1990) Chemistry of Plant Protection 4: Synthetic pyrethroid insecticides: structures and properties. Springer, New York

Hinks CF, Byers JR (1976) Biosystematics of the genus Euxoa (Lepidoptera: Noctuidae). V. Rearing procedures and life cycles of 36 species. Can Entomol 108:1345-1357

Hooper MJ, Ankley GT, Cristol DA, Maryoung LA, Noyes PD,Pinkerton KE (2013) Interactions between chemical and climate stressors: A role for mechanistic toxicology in assessing climate change risks. Environ Toxicol Chem 32:32-48. https://doi.org/10.1002/etc.2043

Johnson M, Luukinen B, Buhl K, Stone D (2010) Deltamethrin Technical Fact Sheet. National Pesticide Information Center, Oregon State University Extension Services. http://npic.orst.edu/factsheets/archive/Deltatech.html

Kehat M, Gordon D (1975) Mating, longevity, fertility and fecundity of the cotton leaf-worm, Spodoptera littoralis (Boisd.) (Lepidoptera: Noctuidea). Phytoparasitica 3:87-102

Khafagi WE, Hegazi EM, Aamer NA (2016) Effects of temperature on the development, food consumption and utilization parameters of the last two larval instars of Spodoptera littoralis (Boisd.). J Agric Sci Technol 2:93-99 
Köhler HR, Triebskorn R (2013) Wildlife ecotoxicology of pesticides: can we track effects to the population level and beyond? Science 341:759-765. https://doi.org/10.1126/science.1237591

Kraikrathok C, Ngamsaeng S, Bullangpoti V, Pluempanupat W, Koul O (2013) Bio efficacy of some Piperaceae plant extracts against Plutella xylostella L. (Lepidoptera: Plutellidae). Comm Appl Biol Sci 78:305-309

Lalouette L, Pottier MA, Wycke MA, Boitard C, Bozzolan F, Maria A, Demondion E, Chertemps T, Lucas P, Renault D, Maibeche M, Siaussat D (2016) Unexpected effects of sublethal doses of insecticide on the peripheral olfactory response and sexual behavior in a pest insect. Environ Sci Pollut $R$ 23:3073-3085. https://doi.org/10.1007/s11356-015-5923-3

Lee CY, Yap HH, Chong NL (1998) Sublethal effects of deltamethrin and propoxur on longevity and reproduction of German cockroaches, Blattella germanica. Entomol Exp Appl 89:137-145. https://doi.org/10.1046/j.1570-7458.1998.00392.x

Legendre S, Clobert J (1995) ULM, a software for conservation and evolutionary biologists. J Appl Stat 22:817-834

Metcalf CJE, Pavard S (2007) Why evolutionary biologists should be demographers. Trends Ecol Evol 22:205-212. https://doi.org/10.1016/j.tree.2006.12.001

Miles M, Lysandrou M (2002) Evidence for negative cross resistance to insecticides in field collected Spodoptera littoralis (Boisd.) from Lebanon in laboratory bioassays. Meded Rijksuniv Gent Fak Landbouwkd Toegep Biol Wet 67:665-669

Moe SJ, De Schamphelaere K, Clements WH, Sorensen MT, Van den Brink PJ, Liess M (2013) Combined and interactive effects of global climate change and toxicants on 
populations and communities. Environ Toxicol Chem 32:49-61.

https://doi.org/10.1002/etc.2045

Riskallah MR (1980) Reduced sensitivity of cholinesterase as a factor of resistance in leptophos selected strain in the Egyptian cotton leafworm. J Environ Sci Heal B $15: 181-92$

Riskallah MR (1984) Influence of posttreatment temperature on the toxicity of pyrethroid insecticides to susceptible and resistant larvae of the Egyptian cotton leafworm, Spodoptera littoralis (Boisd.). Experientia 40:188-190

Sgolastra F, Arnan X, Cabbri R, Isani G, Medrzycki P, Teper, D, Bosch, J (2018) Combined exposure to sublethal concentrations of an insecticide and a fungicide affect feeding, ovary development and longevity in a solitary bee. P Roy Soc B-Biol Sci 285. https://doi.org/10.1098/rspb.2018.0887

Sharma N, Banerjee H, Pal S, Sharma KK (2018) Persistence of thiacloprid and deltamethrin residues in tea grown at different locations of North-East India. Food Chem 253:8892. https://doi.org/10.1016/j.foodchem.2018.01.132

Sinclair BJ, Marshall KE, Sewell MA, Levesque DL, Willett CS, Slotsbo S, Dong Y, Harley CDG, Marshall DJ, Helmuth BS, and Huey RB (2016) Can we predict ectotherm responses to climate change using thermal performance curves and body temperatures? Ecol Lett 19:1372-1385. https://doi.org/10.1111/ele.12686

Soderlund DM (2004) Pyrethroids and sodium channels. In: Beadle DJ, Mellor IR, Usherwood PNR (eds). Neurotox' 03: neurotoxicological targets from functional genomics and proteomics. Society of Chemical Industry, London, p 79e86

Stearns SC (1992) The Evolution of Life Histories. Oxford University Press, Oxford 
WHO (1989) Deltamethrin health and safety guide $N^{\circ} 30$. IPCS International Programme On Chemical Safety. World Health Organization, Geneva, ISBN 9241543515

Yang ZH, Du JW (2003) Effects of sublethal deltamethrin on the chemical communication system and PBAN activity of Asian corn borer, Ostrinia furnacalis (Güenee). J Chem Ecol 29:1611-1619. https://doi-org.inee.bib.cnrs.fr/10.1023/A:1024222830332 


\section{Figure Legends}

Fig. 1 Effect of the deltamethrin treatments on the larval survival rate until pupation of the two experimental cohorts of L4 larvae; sample sizes were 30 larvae per treatment and cohort

Fig. 2 Effect of the deltamethrin treatments on the adult survival rate of males and females; the numbers indicate the sample sizes, and vertical lines represent s.e.m. between experimental replicates

Fig. 3 Effect of the deltamethrin treatments on clutch size in the three experimental series: treatment of both parents versus only females versus only males; the numbers indicate the sample sizes, and vertical lines represent s.e.m. between treated adults

Fig. 4 Effect of the deltamethrin treatments in males on the frequency of successful clutches; the curves indicate the predicted relationships from logistic regression between clutch success (binomial variable for clutches with at least $95 \%$ hatched eggs versus clutches with more than $5 \%$ unhatched eggs) and clutch size

Fig. 5 Effect of deltamethrin on the multiplication rate of simulated populations with the combined values resulting from the experimental treatments at all stages and from the treatments applied specifically to the different developmental stages and sexes; the lowest concentration $(0.076 \mathrm{mg} / \mathrm{L})$ of deltamethrin is not shown because it did not cause significant differences compared to the control group 


\section{FIGURE 1}

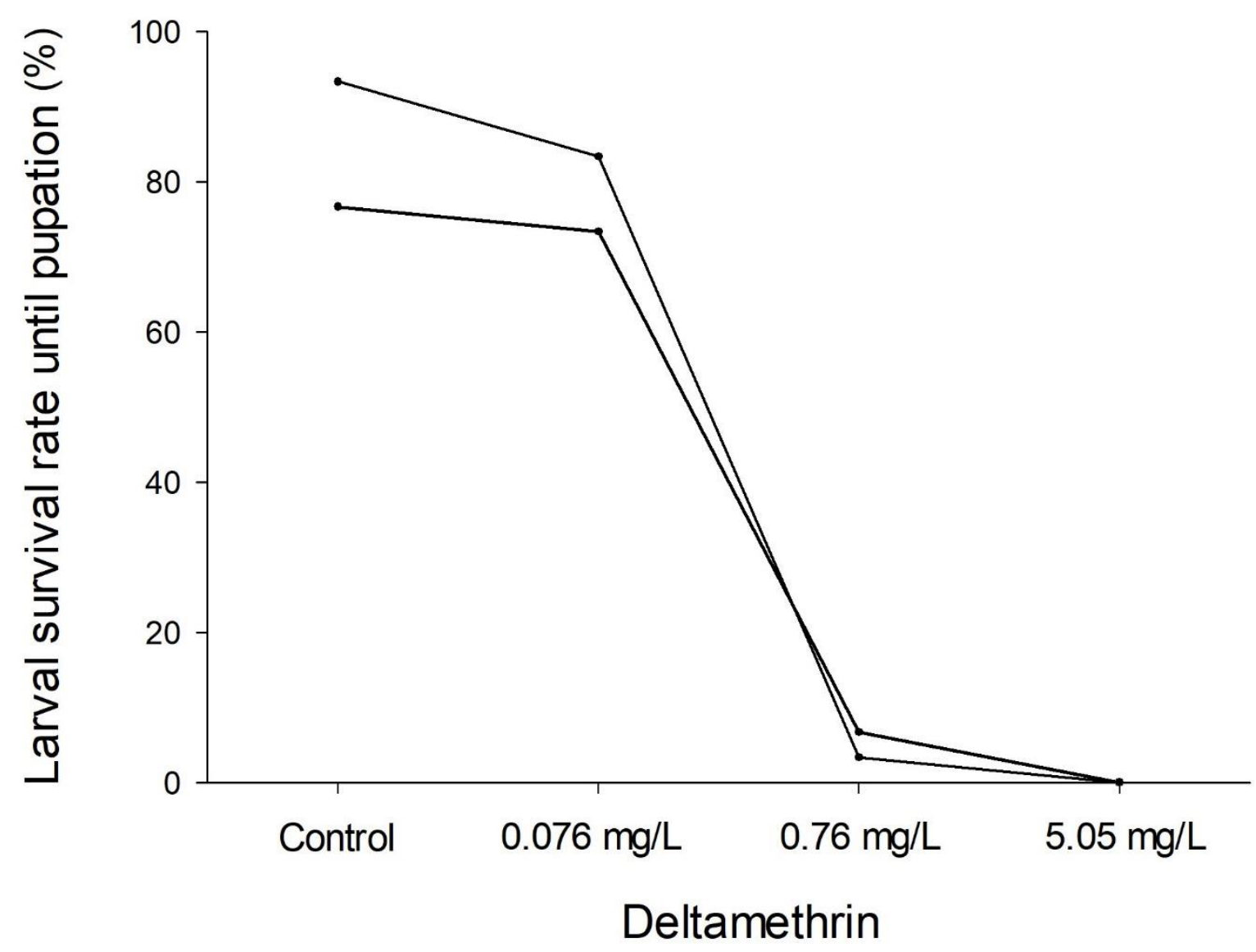




\section{FIGURE 2}

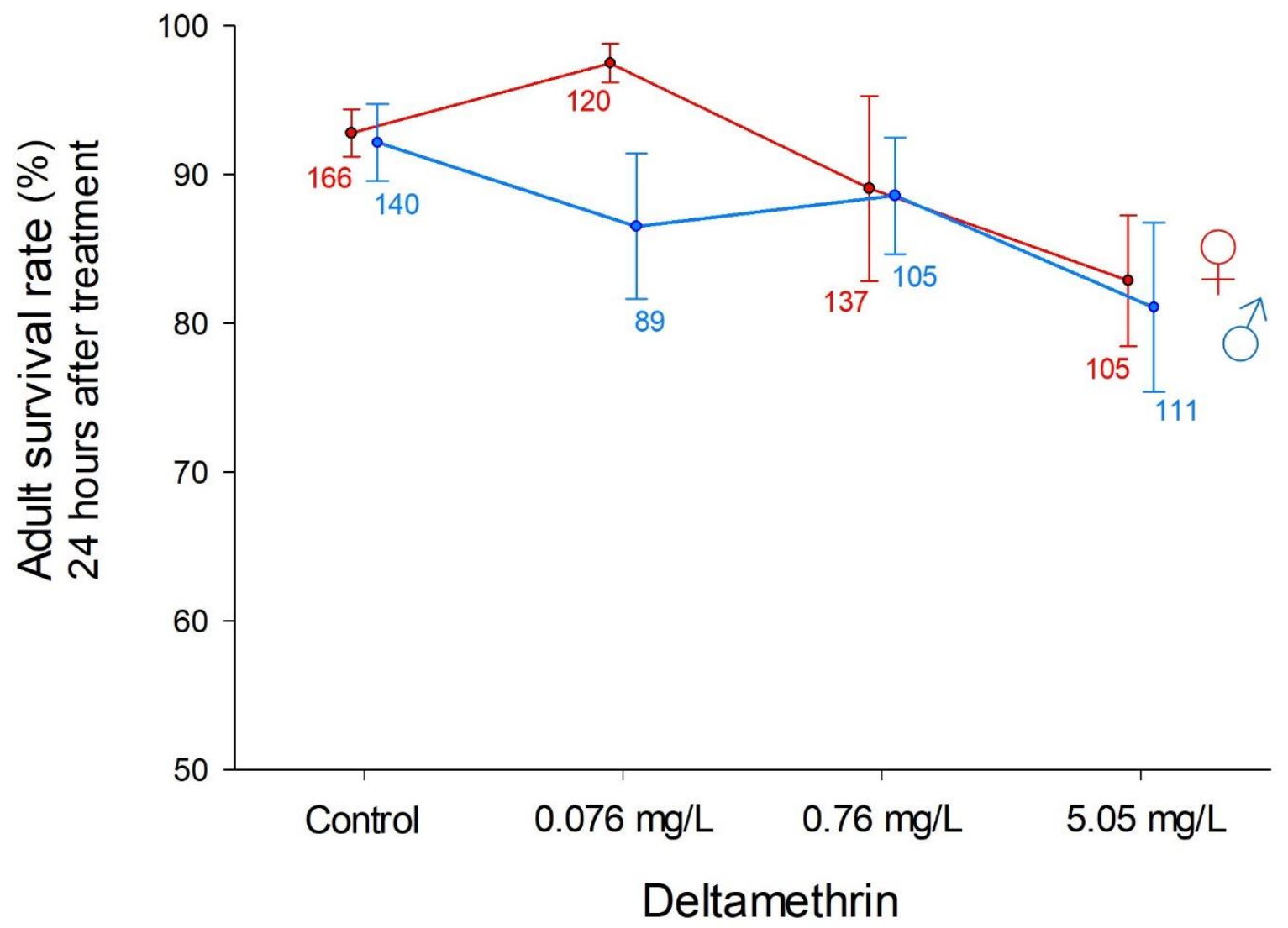




\section{FIGURE 3}

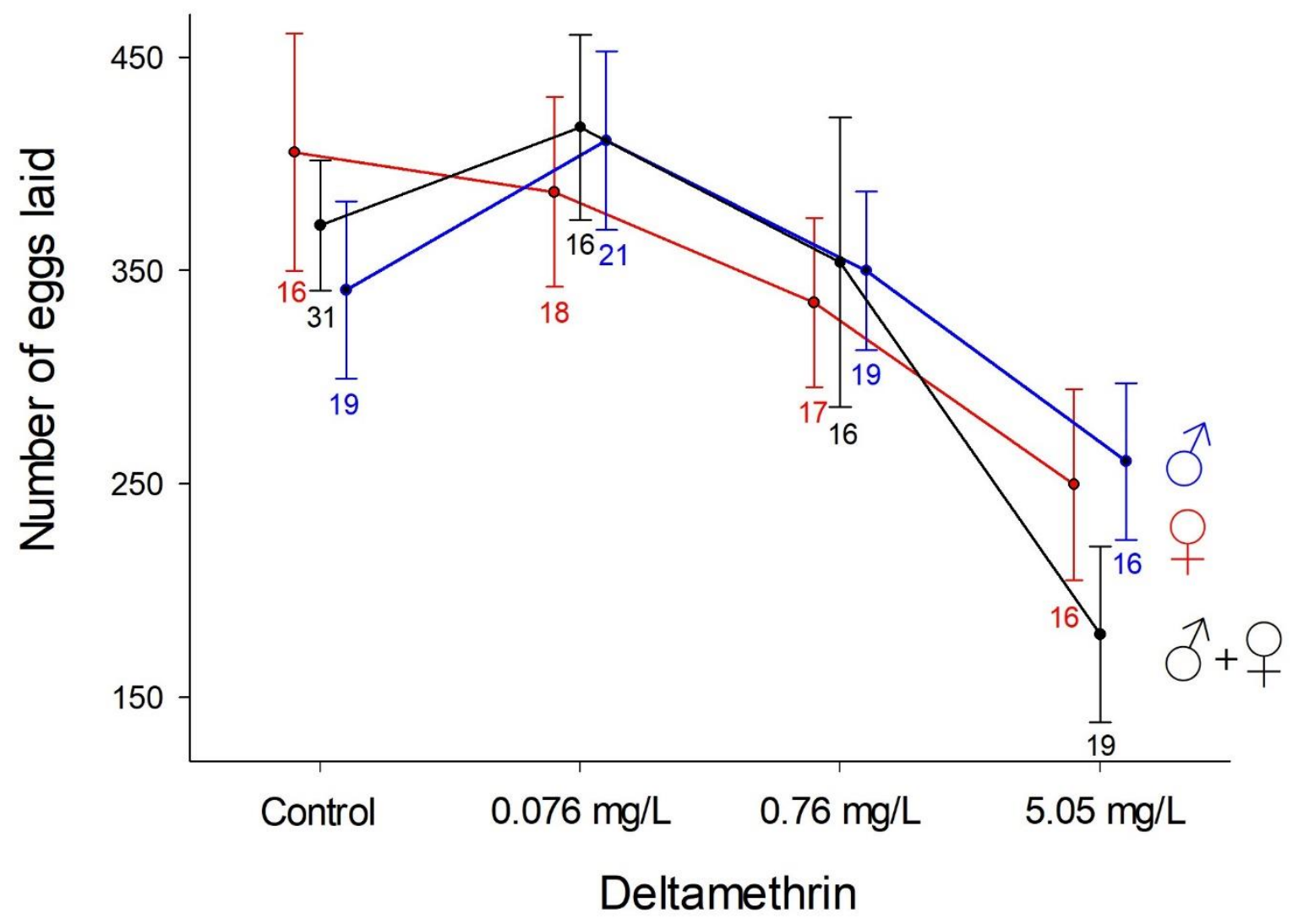




\section{FIGURE 4}

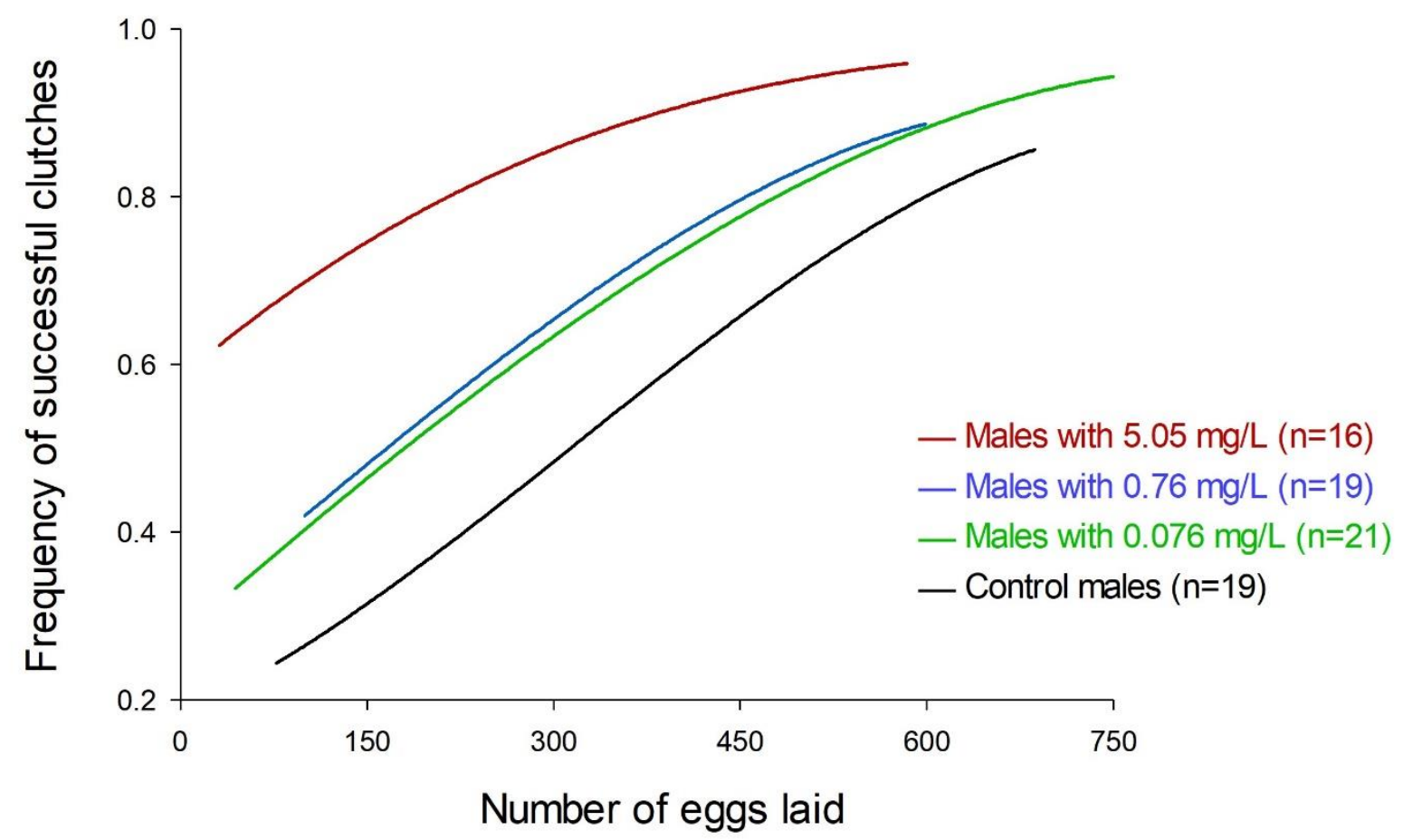




\section{FIGURE 5}

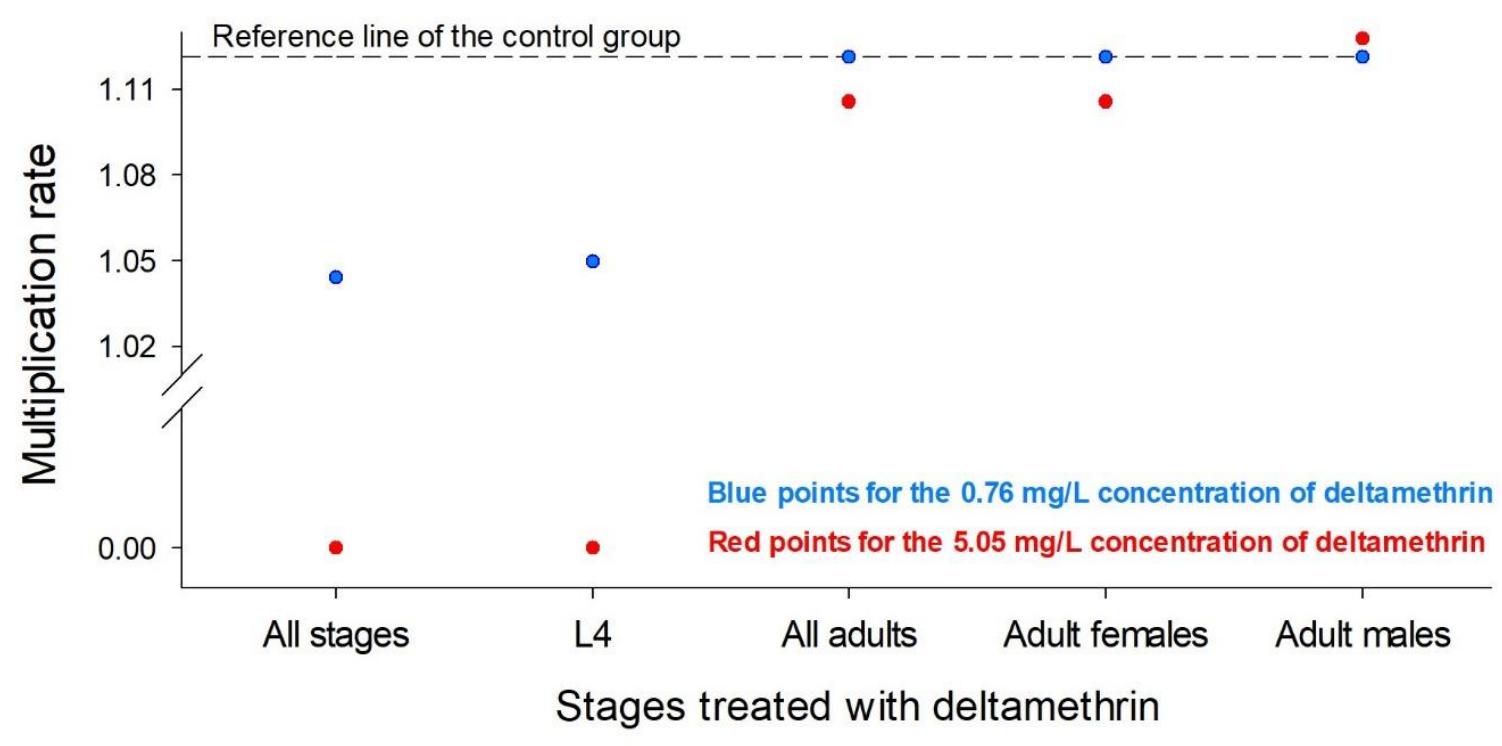


ESM 1. Sample sizes for the four deltamethrin treatments in experimental series performed on survival of L4 larvae, adult survival, and reproduction (number of eggs laid, clutch success). The numbers in the table indicate the sample size of the different experimental dates.

\section{Deltamethrin treatments}

\begin{tabular}{|c|c|c|c|c|}
\hline Experimental series & Control & $0.076 \mathrm{mg} / \mathrm{L}$ & $0.76 \mathrm{mg} / \mathrm{L}$ & $5.05 \mathrm{mg} / \mathrm{L}$ \\
\hline Survival of L4 larvae & 30,30 & 30,30 & 30,30 & 30,30 \\
\hline Survival of adult females & $24,25,48,35,22,12$ & $24,27,35,20,14,0$ & $24,10,54,35,14,0$ & $28,10,10,20,22,15$ \\
\hline Survival of adult males & $15,16,19,17,21,21,17,7,7$ & $15,17,6,6,4,10,17,7,7$ & $14,4,23,17,6,10,17,7,7$ & $17,4,6,10,24,19,17,7,7$ \\
\hline Reproduction with both parents treated & $4,7,10,4,3,3$ & $4,6,0,0,0,6$ & $4,0,8,0,0,4$ & $4,0,0,7,8,0$ \\
\hline Reproduction with females treated & $4,4,4,4$ & $5,5,4,4$ & $6,3,4,4$ & $6,4,3,3$ \\
\hline Reproduction with males treated & $3,2,4,3,4,3$ & $4,3,5,1,3,5$ & $2,2,5,4,3,3$ & $1,1,4,3,2,5$ \\
\hline
\end{tabular}


ESM 2. Values of the parameters used in matrix models. The values reported in bold are for the significant responses to deltamethrin we found, and for which we modelled values that differed from the control group. For the hatching success, we performed the model with the specific value we estimated for the $5.05 \mathrm{mg} / \mathrm{L}$ concentration of deltamethrin applied only to males (value in bold), and also the models with no significant effect of deltamethrin for the cases with the treatment applied to females or both sexes.

\begin{tabular}{rcccc}
\hline Deltamethrin treatment & Control & $\mathbf{0 . 0 7 6} \mathbf{~ m g} / \mathbf{L}$ & $\mathbf{0 . 7 6} \mathbf{~ m g} / \mathbf{L}$ & $\mathbf{5 . 0 5} \mathbf{~ m g} / \mathbf{L}$ \\
\hline Purval survival (\%) & 96.7 & 96.7 & $\mathbf{7 6 . 9}$ & $\mathbf{7 4 . 1}$ \\
Adult female survival (\%) & 92.8 & 92.8 & 92.8 & $\mathbf{8 2 . 9}$ \\
Number of eggs laid & 371 & 371 & 371 & $\mathbf{2 2 7}$ \\
Hatching success (\%) & 71.3 & 71.3 & 71.3 & 71.3 or $\mathbf{9 1 . 1}$ \\
\hline
\end{tabular}

For other parameters used in models, their values were obtained in a complementary study (spring 2017): $68.0 \%$ of larval survival from L1 to L4 stages, sex-ratio with $47.1 \%$ of females, $78.3 \%$ of laying after mating, duration of 4 days for the incubation period, duration of 9 days for the period from L1 to L4 stages, duration of 13 days for the period between L4 stage and pupation, and duration of 15 days for the pupal period. 
ESM 3. Relationship between the number of clutches and the numbers of L4 larvae at the first and second generation (same relationship but respectively for the scales at left and right). These projections were performed from the values of vital parameters reported for the control group in the Table ESM 1 (Online Resource 1).

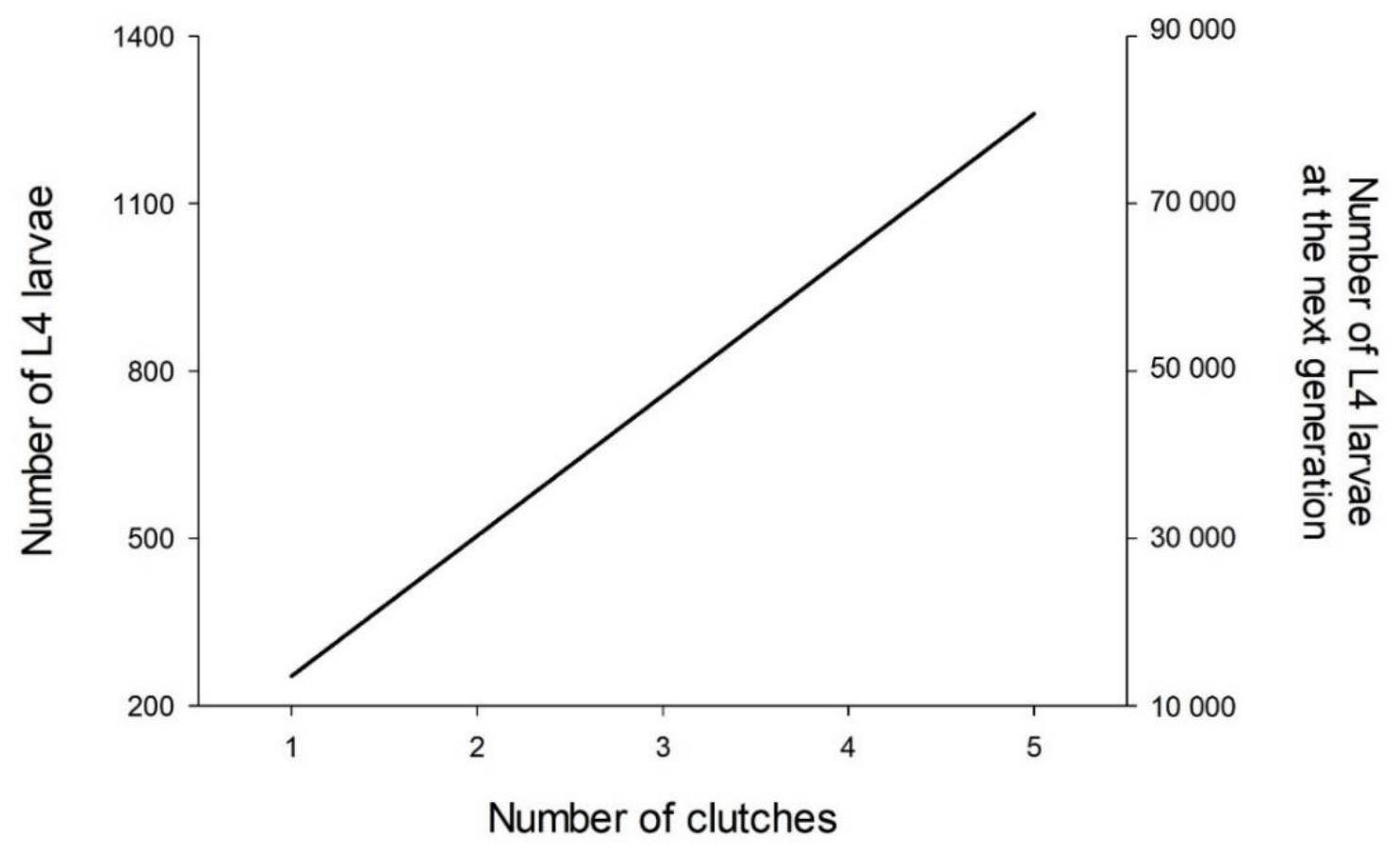


ESM 4. Effect of the deltamethrin treatments over time on the cumulative percentage of surviving larvae from L4 stage to pupation. Sample sizes were of 45 larvae for each treatment (control group, concentrations 0.76 and $5.05 \mathrm{mg} / \mathrm{L}$ of deltamethrin) applied to the fourth larval stage. This experiment was performed in February 2019 in the same laboratory conditions (temperature, humidity, food, larval density) than the main experimental series. If the curve of the $0.76 \mathrm{mg} / \mathrm{L}$ concentration did not significantly differ from the control group (Wilcoxon test: $X^{2}{ }_{1}=1.0 P=0.312$ ), a significant difference was found between the control group and the $5.05 \mathrm{mg} / \mathrm{L}$ concentration $\left(X^{2}{ }_{1}=46.7 P<0.0001\right)$. This effect of the highest concentration of deltamethrin took effect in less than 2 days.

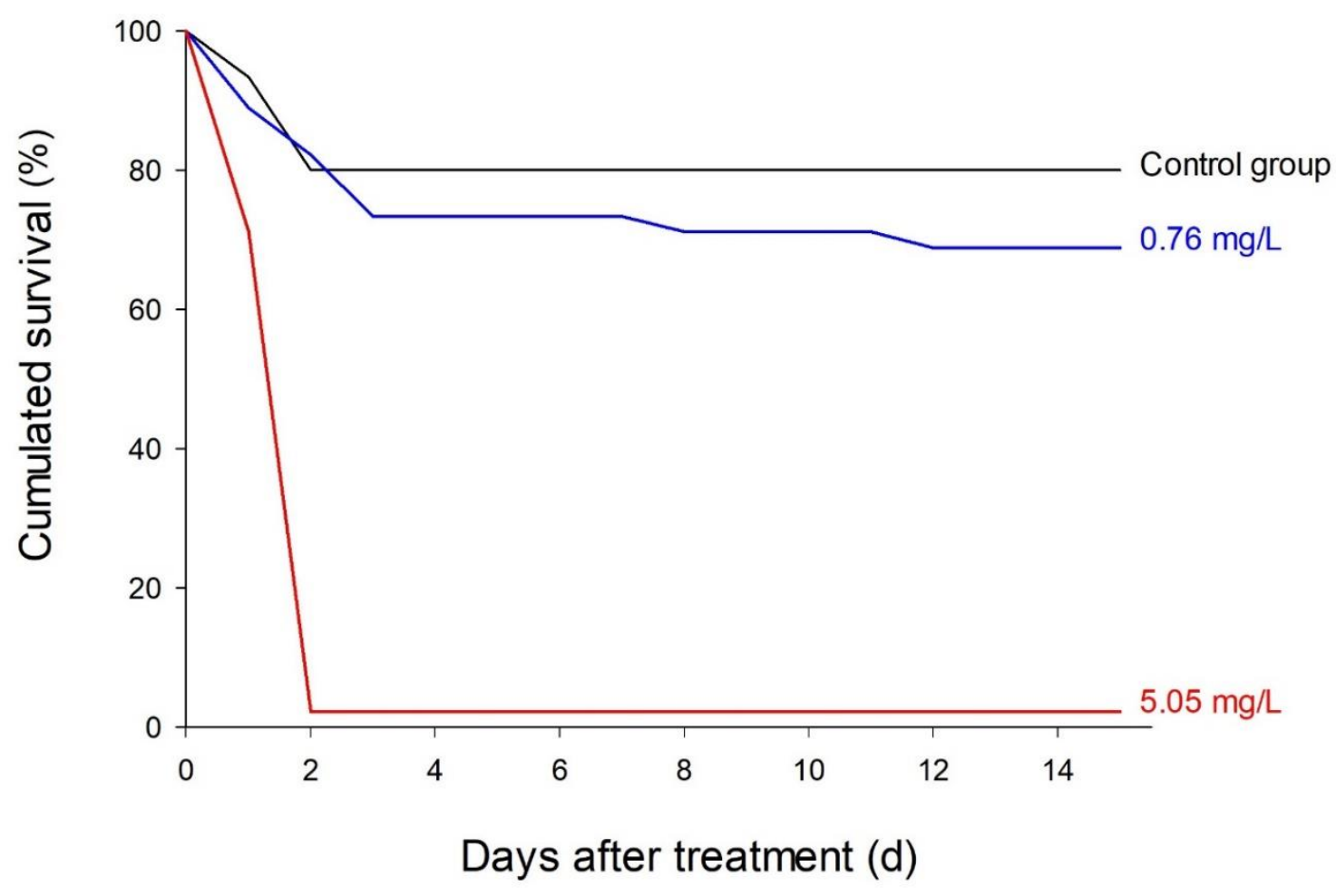

